\title{
Ocorrência de papilomavírus humano na cérvice uterina de mulheres da região ocidental da Amazônia Brasileira
}

\author{
Jéfferson Castro DOS SANTOS ${ }^{1}$, Marinês Rodrigues dos Santos CEZAR², Maillene Rodrigues LISBOA3, \\ Maria Manuela da Fonseca MOURA ${ }^{4}$
}

\section{RESUMO}

A ocorrência do papiloma vírus humano (HPV) é um problema de saúde pública, pois tem sido associado ao câncer. O objetivo da pesquisa foi identificar a ocorrência de papilomavírus humano na cérvice uterina de mulheres da regiáo ocidental da Amazônia Brasileira. O estudo foi realizado na capital de Rondônia, Porto Velho. Foram identificados os tipos de HPV e resultados moleculares foram correlacionados com aqueles os testes colpocitológicos de amostras provenientes de 334 mulheres que realizaram exames preventivos no Sistema Único de Saúde. Obteve-se o material genético viral do papilomavírus humano (DNA-HPV) e o fragmento de $450 \mathrm{pb}$ da regiáo conservada do gene L1 amplificado e submetido à análise do polimorfismo dos fragmentos de restrição (RFLP). Das 334 amostras analisadas, $31 \%$ foram confirmados com a presença de material viral (DNA-HPV). Confirmou-se a existência dos tipos: HPVS-16, 18, 33, 53 e 58, que identificam o grupo de alto risco oncogênico com 72\% (74/103) de ocorrência, bem como os HPVS-11, 42 e 44 pertencentes ao grupo de baixo risco oncogênico com $28 \%$ de ocorrência. Os perfis recorrentes durante o desenvolvimento da análise foram do HPV-16 e -18 com 17\% e 16\%, respectivamente. Os resultados da pesquisa indicam que mais de $80 \%$ das amostras analisadas e que continham material viral não apresentavam nenhuma alteração celular no teste citológico, o que reforça a necessidade de se difundir o uso das técnicas moleculares em diagnósticos convencionais.

PALAVRAS-CHAVE: Reação em Cadeia da Polimerase, Câncer urogenital, Papilomavírus humano, Biologia molecular.

\section{Occurrence of human papillomavirus in uterine cervix of women in the western Brazilian Amazon}

\begin{abstract}
The occurrence of human papillomavirus (HPV) is a public health problem, because it has been linked to cancer. The aim of this research was to identify the occurrence of human papillomavirus in uterine cervix of women in the western Brazilian Amazon. The study was conducted in the capital of Rondonia, Porto Velho. We identified the types of HPV, also we correlated molecular results with those of colpocytologic tests coming from 334 women who underwent preventive examinations at the Brazilian Unified Health System. From samples, we obtained genetic material of the human papillomavirus (HPV ADN) and amplified the 450-bp fragment from the conserved region of the L1 gene, which was submitted to restriction fragment length polymorphism (RFLP) analysis. Of the 334 samples analyzed, $31 \%$ were confirmed to have the presence of viral material (HPV ADN). We detected the existence of the following HPV types: 16, 18, 33, 53 and 58, which identifies the group of high oncogenic risk, with 72\% (74/103) of occurrence. Also we found HPV types 11, 42 and 44, which belong to the group of low oncogenic risk, with $28 \%$ of occurrence. The recurrent profiles in the development of the analysis were HPV-16 and -18 , with $17 \%$ and $16 \%$ respectively. We found that more than $80 \%$ of the samples that contained viral material did not show any abnormal cell in the cytology test. This finding reinforces the need to disseminate the use of molecular techniques in conventional diagnostics.
\end{abstract}

KEYWORDS: Polymerase chain reaction, Urogenital cancer, Human papillomavirus, Molecular biology.

\footnotetext{
1 Universidade Federal de Rondônia (UNIR), Campus - BR 364, Km 9,5; CEP: 78900-000; Porto Velho- R0. Fone: (69) 2182-2100, - E-mail: jeffersoncastrodossantos@gmail.com

2 UNIR, Departamento de Enfermagem. E-mail: dramarines@hotmail.com

${ }^{3}$ UNIR, Departamento de Medicina. E-mail: maillenelisboa@gmail.com

${ }^{4}$ UNIR, Centro Interdepartamental de Biologia Experimental e Biotecnologia-CIBEBI; E-mail: mmoura33@hotmail.com.br
} 


\section{INTRODUÇÃO}

O papiloma vírus humano (HPV) é um vírus detectado entre $10 \%$ e $20 \%$ da populaçáo sexualmente ativa, entre 15 e 49 anos de idade, sendo encontrado em mais de $90 \%$ dos casos para neoplasias no epitélio uterino (INCA 2008). O HPV ocasiona infecçóes na região anogenital, tendo sido relacionado a vários tipos de cânceres (Pereyra et al. 2000).

$\mathrm{O}$ avanço das técnicas moleculares ao longo da última década possibilitou identificar e classificar o HPV em seus tipos, subtipos e variantes com precisão. Estas denominaçôes são realizadas conforme a divergência genômica de L1, a regiáo mais conservada dos HPV (Castro et al. 2004).

O potencial oncogênico do HPV depende de três fatores: o tipo viral, a persistência e a integração do DNA viral e a célula hospedeira. A análise dos fatores possibilita que se agrupe de acordo com a composiçấo em HPV de baixo risco oncogênico (HPV-6, -11, -30, -42, -43 e -44...), encontrados em lesóes intra-epiteliais de baixo grau (LSIL) e HPV; e HPV de alto risco oncogênico (HPV-16, -18, -31, -33, -35, -39, $-45,-51,-52,-56,-58,-59$ e $-68 \ldots)$, encontrados em lesóes intra-epiteliais de alto grau (HSIL) e em cânceres cervicais que se manifestam sempre como lesóes monoclonais.

No Brasil, o HPV-16 é o que mais prevalece em todas as regiōes, já o HPV-18 encontra-se em segundo lugar nas regiôes Norte, Sudeste e Sul; seguido pelo HPV-31 e HPV-33 nas regiôes Nordeste e Central (INCA 2008).

A reação em cadeia da polimerase (PCR), hibridizaçáo in situ e ou captura híbrida I e II, apresenta uma eficiência de 95\% a 100\% em relação às técnicas citopatologicas, independente da origem do material clinico analisado. Constatou-se que a variaçáo ocorre devido ao processo de coleta, conservação do material clínico coletado, bem como seu armazenamento pós-extração do DNA viral (Bosch et al. 2002; de Villiers et al. 2004), ou seja, os resultados da coleta vão variar de acordo com as condiçóes da coleta e armazenamento, incidindo diretamente nos resultados. No município de Porto Velho, Rondônia o diagnóstico do preventivo é realizado por técnicas convencionais da citologia oncótica. Em função do desconhecimento dos tipos e grupos oncogênicos, foi proposto para o presente estudo o rastreamento do material genético viral do papiloma vírus humano (DNA-HPV) por PCR, assim como o traçado do perfil eletroforético por análise do polimorfismo dos fragmentos de restrição (RFLP), com a intenção de se obter o perfil epidemiológico dos HPV circulantes na regiấo coberta pela investigação.

\section{MATERIAL E MÉTODOS}

O presente estudo foi realizado entre os meses de agosto de 2008 e agosto de 2009, tendo sido aprovado pelo Comitê de Ética em Pesquisa do Núcleo de Saúde - CEP/NUSAU (FR:
214785; Carta 018/CEP/NUSAU) da Universidade Federal de Rondônia/ UNIR.

O Centro de Referência da Saúde da Mulher (CRSM) foi o espaço selecionado para composiçáo da amostra. Localiza-se nas dependências da Policlínica Rafael Vaz e Silva, no centro da cidade de Porto Velho no bairro conhecido por Liberdade, e atende as mulheres do bairro e adjacências para todas as patologias. No caso de mulheres diagnosticadas com HPV por meio de citologia de positividade para o HPV é formalizado o indicativo para as outras unidades ligadas ao Sistema Único de Saúde/SUS do município, que possam dar conta de possibilitar uma análise mais precisa e posterior tratamento.

Todas as mulheres que procuraram o CRSM nesse período aceitaram participar do estudo, perfazendo um total de 334 amostras, sendo a totalidade pacientes do SUS na faixa etária entre 15/45 anos. O procedimento de coleta das amostras provenientes da cérvice uterina foi realizado após o esclarecimento do objetivo, obtençáo do consentimento livre, bem como e explicitado e sanado todas as dúvidas referentes à aplicação de questionário sócio-cultural do presente estudo.

A profissional de enfermagem em atividade no próprio CRSM, no ato do exame citopatológico convencional (Papanicolaou), conforme preconizado pelo Ministério da Saúde (INCA 2008), colaborou com a coleta do material cérvico-vaginal, o qual foi dividido em duas partes: uma para o laboratório citopatológico do próprio Centro de Referência da Saúde da Mulher e outra parte foi acondicionada em tubos Vacuntainer, de $5 \mathrm{ml}$ contendo $400 \mu \mathrm{L}$ de tampáo TE I (Tris-HCl 10 mM; EDTA 1 mM pH 8,0 e Tween $10 \%$ ), as quais foram acondicionadas em freezer do Centro Interdepartamental de Biologia Experimental e BiotecnologiaCIBEBI, que fica localizado no Campus da Universidade Federal de Rondônia - UNIR (CIBEBI/UNIR), que apresenta as condiçôes ideais para realização das técnicas moleculares (PCR-RFLP). A investigação envolveu as seguintes etapas:

Extração DNA/HPV: O material genético viral do Papilomavírus humano (DNA/HPV) foi obtido colocando as amostras que estavam armazenadas em $400 \mu \mathrm{L}$ de TE I, em banho-maria (incubação) por 2 horas a $65^{\circ} \mathrm{C}$. Após, decorrida esta etapa, o material foi resfriado a $37^{\circ} \mathrm{C}$, adicionado $5 \mu \mathrm{L}$ de tampão TPK (tampão proteolítico proteinase $\mathrm{K} 10 \mathrm{mg}$ $\mathrm{mL}^{-1}$ ) e incubado por 3 horas ou overnight.

Após a incubação foram retiradas as escovinhas com cerdas e acrescentados $500 \mu \mathrm{L}$ de clorofórmio, e centrifugado por 3 minutos a $13000 \mathrm{~g}$.

O sobrenadante foi transferido para um tubo de $1,5 \mathrm{ml}$ e adicionado $500 \mu \mathrm{L}$ de etanol, deixando por 5 minutos. Após este procedimento foi homogeneizado levemente e centrifugado por mais 5 minutos a $12000 \mathrm{~g}$. Descartou-se o sobrenadante e o precipitado foi ressuspenso em tampáo 
TE II (Tris-HCl 10 mM; EDTA 1 mM; pH 8,0), para armazenamento no freezer.

A amplificação da região L1 do DNA/HPV foi realizada por técnica da reaçáo em cadeia da polimerase PCR na mix de reaçáo com volume final de $25 \mu \mathrm{L}$, composto de água Milli-Q autoclavada; $10 \mathrm{pmol} \mu \mathrm{L}^{-1}$ de cada primer: (5'-CgTCCMAARggAWACTgATC-3') e (5'-gCMCAgggWCATAAYAATgg-3'); $200 \mu \mathrm{M}$ de cada dNTPs; $200 \mathrm{mM}$ de Tampão Buffer 10x (50 mM de $\mathrm{KCl} \mathrm{e}$ $10 \mathrm{mM}$ de Tris- $\mathrm{HCl}(\mathrm{pH} 8,5)) ; 1,5 \mathrm{mM}$ de $\mathrm{MgCl}_{2}(50 \mathrm{mM}$ ); 1,5 unidade de Taq DNA polimerase, todos os reagentes da Invitrogen, São Paulo e $3 \mu \mathrm{L}$ de DNA por reação.

O programa utilizado no termociclador Mastercycler Gradiente (Eppendorf, Alemanha) foi de $94^{\circ} \mathrm{C}$ por 3 minutos (Pré-aquecimento), seguido por 32 ciclos de $94^{\circ} \mathrm{C}$ por 1 minuto (desnaturação), $56^{\circ} \mathrm{C}$ por 1 minuto (pareamento) e $72{ }^{\circ} \mathrm{C}$ por 1 minuto (elongação). Acrescentou-se mais 1 minuto a $72{ }^{\circ} \mathrm{C}$ (finalização) e foi mantida a temperatura a $4^{\circ} \mathrm{C}$ (Hold), conforme (Bernard et al. 1994). A visualização do produto da PCR correspondente ao fragmento de $450 \mathrm{pb}$ foi realizado em gel de agarose a 1,5\% corado com brometo de etídio $1 \mu \mathrm{g} \mathrm{mL} \mathrm{m}^{-1}$, Figura 1 .

A caracterização dos tipos de HPV foi realizada por RFLP, com as enzimas de restrição, Bam HI, DdeI, Hae III, Hinf I, Pst I, Rsa I e Sau 3AI (Prodimol Biotecnologia S/A, Belo Horizonte), que reconhecem e clivam o sítios polimórficos existentes na regiáo L1 para obter o perfil eletroforético (Kaneshima et al. 2001). A visualização do produto da digestáo enzimática foi realizado em gel de agarose a $3 \%$ corado com brometo de etídio $1 \mu \mathrm{g} \mathrm{mL}^{-1}$, como observado na Figura 2 .

A análise citológica foi realizada e fornecida pelo laboratório do Centro de Referência da Saúde da Mulher, descrita segundo a classificação do Sistema de Bethesda 2001

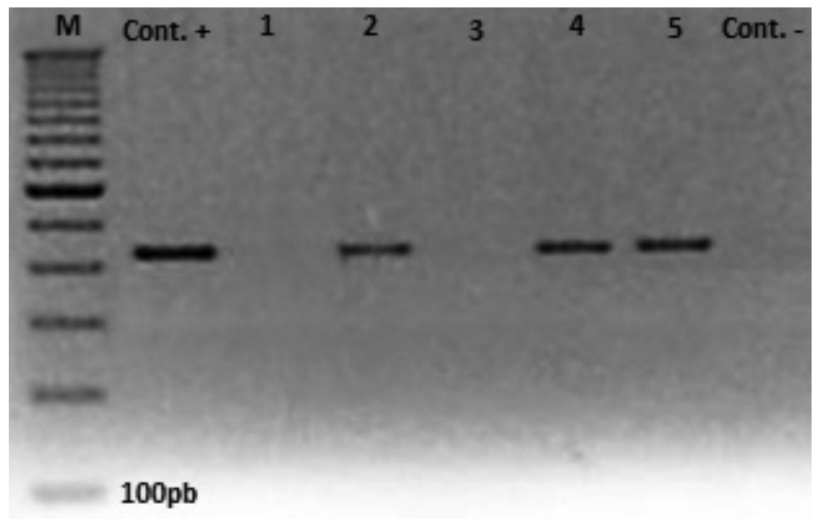

Figura 1 - Amplificação do material genético viral correspondente à região conservada do gene L1 do Papilomavírus Humanos (HPV). M: marcador de 100pb; Cont.+: controle positivo da presença do DNA-HPV; Linhas 1 e 3 confirmação da ausência do material genético viral; Linhas 2, 4 e 5 confirmação do material genético viral do HPV; Cont.- : controle de contaminação da reação.

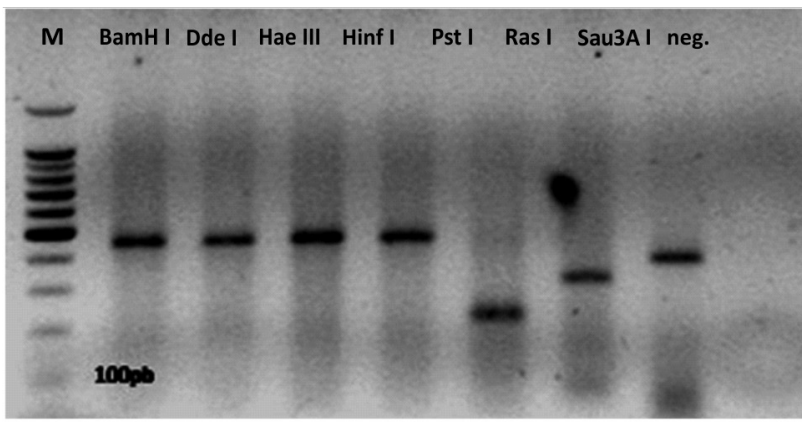

Figura 2 - Perfil eletroforético do HPV-16 por RFLP. Linhas M: marcador de 100pb; neg.: controle negativo de contaminação.

(Solomon et al. 2002). A análise das variáveis foi realizada pelo teste qui-quadrado de Pearson convencional. O nível de significância alfa pré-fixado foi de 5\%.

\section{RESULTADOS E DISCUSSÃO}

A presença do papilomavírus humano foi observada em 31\% (103/334) das amostras analisadas (Tabela 1). De acordo com Bosch et al. (2002), em estudo de caso controle com amostras provenientes da cérvice uterina é observado a presença de HPV na faixa e $90 \%$ a $100 \%$, com o auxílio de técnicas moleculares. No Brasil, estudos similares observaram a presença do HPV entre 73,9\% a 95\% das amostras (Noronha et al. 1999; Cavalcanti et al. 2000; Oliveira et al. 2003).

Tabela 1 - Comparação dos resultados colpocitológicos com os resultados moleculares quanto à presença ou ausência do DNA-HPV.

\begin{tabular}{lccc}
\hline \multirow{2}{*}{ Citologia } & $\mathrm{N}$ & \multicolumn{2}{c}{ DNA-HPV } \\
\cline { 3 - 4 } & & (ausência) & (presença) \\
\hline Alterada & 16 & 0 & $16(5 \%)$ \\
Normal & 318 & $231(69 \%)$ & $87(26 \%)$ \\
\hline Total & 334 & 231 & $103(31 \%)$ \\
\hline
\end{tabular}

As variaçóes encontradas nos trabalhos citados e a porcentagem de HPV observada no presente estudo, deve-se a dois fatores: os trabalhos citados correlacionam os resultados do uso de diferentes técnicas moleculares na metodologia como, por exemplo, PCR, RFLP, hibridizaçáo in situ e ou captura híbrida I e II. Estas ferramentas apresentam diferenças quanto aos reagentes utilizados devido às suas especificidades e sensibilidades em relação ao material pesquisado. Em segundo lugar é preciso considerar que o presente estudo realizou coleta de forma aleatória. Todas as 334 mulheres abordadas aceitaram participar, porém não havia o prévio conhecimento de anormalidades na cérvice uterina, mostrando uma visão epidemiológica. As citaçôes utilizaram amostras de caso controle para verificar a eficiência do método molecular empregado, o que explica a baixa percentagem de HPV observado no presente estudo em relação aos estudos 
objeto das citaçóes. Entretanto, os fatores considerados náo influenciam na eficiência em relaçáo ao diagnóstico molecular.

Nos resultados citológicos trabalhos como os de Franco et al. (2003) e Roberts et al. (2006) relatam uma taxa de falsonegativo em torno de $5 \%$ a $70 \%$, bem como a existência de discordância entre diferentes citologistas em torno de $10 \%$ a $80 \%$. Ao correlacionar os dois métodos (citológico e molecular), quanto à presença ou ausência do Papilomavírus humano (Tabela 1), o presente estudo obteve uma similaridade absoluta em 5\% (16/334) das amostras que apresentavam alteraçôes celulares com indicativo para HPV. Já em 95\% das amostras que não apresentaram qualquer tipo de alteraçáo celular $(318 / 334)$ o resultado molecular revelou a presença do HPV em 26\% (87/318).

Ao realizar a tipagem das amostras com a presença do HPV sem alteraçôes celulares (Tabela 1) observamos o perfil eletroforético de oito genótipos distintos sendo $72 \%$ (74/103) dos tipos de HPV pertencentes ao grupo de alto risco oncogênico: HPV-16 (17\%), HPV-18 (16\%), HPV56 (14\%), HPV-33 (14\%), HPV-53 (10\%) e apenas $28 \%$ (29/103) pertencentes ao grupo de baixo risco oncogênico (Tabela 2): HPV-11 (9\%), HPV-42 (13\%), HPV-44 (7\%). Os estudos realizados por Andersson et al. (2005), Pitta et al. (2009) e Wyant (2008) relatam que o HPV-16 e HPV18 são os mais prevalentes com $76 \%$ dos casos observados e podem ser encontrados associados ou não a outros tipos. Nesta investigação em nenhuma das amostras foi observado mais de um tipo de HPV.

Ao correlacionar os resultados citopatológicos e moleculares de acordo com a classificação do Sistema Bethesda e a tipagem

Tabela 2 - Distribuição dos resultados moleculares e citológicos entre os tipos oncogênicos de HPVs e as alterações celulares segundo o Sistema Bethesda: ASC-US: Alterações celulares escamosas atípicas de significado indeterminado; LSIL: lesões intra-epiteliais escamosas de baixo grau; HLSIL: lesões intra-epiteliais escamosas de alto grau; NIML: Negativo para lesões epiteliais e malignidade.

\begin{tabular}{|c|c|c|c|c|c|c|}
\hline \multirow{2}{*}{$\begin{array}{l}\text { Tipos } \\
\text { Oncogênicos }\end{array}$} & & \multirow{2}{*}{$\%$} & \multicolumn{4}{|c|}{ Citologia } \\
\hline & & & ASC-US & LSIL & HLSIL & NIML \\
\hline \multirow[t]{5}{*}{ Alto Risco } & HPV 16 & 17 & 01 & 02 & & 15 \\
\hline & HPV 18 & 16 & 01 & 02 & 02 & 12 \\
\hline & HPV 33 & 14 & - & - & - & 14 \\
\hline & HPV 53 & 10 & - & - & - & 10 \\
\hline & HPV 56 & 14 & - & - & - & 15 \\
\hline \multirow[t]{3}{*}{ Baixo Risco } & HPV 11 & 9 & - & - & - & 09 \\
\hline & HPV 42 & 13 & - & 01 & - & 12 \\
\hline & HPV 44 & 7 & - & 07 & - & - \\
\hline \multicolumn{2}{|c|}{ Similaridade } & & & $100 \%$ & & $27,35 \%$ \\
\hline
\end{tabular}

dos HPVs de acordo com o potencial oncogênico (Tabela 2), observa-se $27,3 \%$ de mulheres assintomáticas com a presença dos tipos de HPVs pertencentes ao grupo de alto potencial oncogênico. O INCA (2008) preconiza que o preventivo anual é uma das indicaçôes do Ministério da Saúde para prevenção do câncer uterino.

No entanto, o exame colpocitológico tem o caráter morfológico: a grande vantagem das técnicas moleculares é diagnosticar as pacientes assintomáticas, assim esta investigação e seus resultados revelam que há uma necessidade da realização do preventivo mais frequente. Com isso é possível inferir que o risco da paciente desenvolver lesóes mais graves e sua progressão ao câncer seria menor e, por conseguinte a frequência de câncer de colo de útero na população também diminuiria. Desta forma o método molecular além de detectar a presença é capaz de diagnosticar a relevância do agente oncogênico antes de provocar as alteraçóes celulares.

É importante citar a pesquisa desenvolvida por Callahan et al. (1993) a qual revela que os HPV-56 e HPV-53 muitas vezes não apresentam uma expressividade epidemiológica, mas prevalecem em sua especificidade em determinados grupos de risco.

A prevalência do HPV-53 em estudos epidemiológicos no mundo apresentam variação de $0,5 \%$ a $25 \%$ (Stevens et al. 2007). No Brasil observaram a prevalência deste genótipo com variação de 3,0\% a 24,4\% (INCA 2008). No Distrito Federal a prevalência foi de $6,0 \%$ em mulheres HIV-1 soronegativas e de 6,2\% em mulheres HIV-1 soropositivas (Camara et al. 2003).

Stevens et al. (2007) em estudo epidemiológico no mundo observou a prevalência de $0,1 \%$ a $18 \%$ do HPV-56. No Brasil a prevalência varia de $1 \%$ a $11 \%$ (INCA 2008). Rosa (2009) em estudo realizado no Distrito Federal observou o HPV-56 com prevalência de $6,2 \%$ em mulheres HIV-1 soropositivas e, de acordo com os resultados obtidos, não há dados sobre a prevalência do HPV-56 em mulheres soronegativas.

No presente estudo $11 \%$ das mulheres pertencem ao grupo HIV-1, soropositivas; e $89 \%(296 / 334)$ ao grupo HIV-1, soronegativas. O HPV-53 foi observado em 5\% (10/103) em ambos os grupos, já o HPV-56 foi observado somente em mulheres HIV-1 soropositivas com 14\% (15/103). Somente $2 \%$ das mulheres HIV-1 soropositivas foram diagnosticadas por PCR livres da presença do DNA/HPV. Até o presente momento não há na literatura trabalhos que relatem o genótipo HPV-56 fora do grupo soropositivo. Sendo assim, é possível inferir que este genótipo de alguma forma depende do vírus HIV para se estabelecer. 


\section{CONCLUSÃO}

A investigação por método molecular (PCR) revela a presença do DNA-HPV em 31\% (103/334) das amostras, com eficiência em diagnosticar a presença do HPV antes de sua manifestaçấo nas amostras provenientes da cérvice uterina de $27,35 \%$ (87/318). Desta forma observamos que mais de $80 \%$ das amostras analisadas e que continham material viral não apresentavam nenhuma alteração celular no teste citológico, o que reforça a necessidade de se difundir o uso das técnicas moleculares em diagnósticos convencionais.

A técnica de RFLP revelou no presente estudo o perfil eletroforético de oito tipos distintos sendo: cerca de $70 \%$ (74/103) pertencentes ao grupo de alto risco oncogênico e apenas $28 \%$ pertencentes ao grupo de baixo risco oncogênico, todos já descritos na literatura e circulantes em todo o território brasileiro. Com os resultados do presente estudo, têm-se informaçôes regionais que contribuirão para ampliação do debate e parte da trajetória para futuras investigações.

Financiadores: CAPES, CNPq, FINEP

\section{AGRADECIMENTOS}

A Dra ${ }^{a}$. Vera Engracia Gama de Oliveira que possibilitou minha convivência com seu grupo de pesquisa no qual foi possível adquiri formação científica, profissional e ética desde minha trajetória na Iniciaçấo Científica, Mestrado e Doutorado. Aos colegas de pesquisa cito em ordem alfabética: Dr ${ }^{\circ}$. Almeida Andrade Casseb, Dra ${ }^{a}$. Francisca de Jesus Holanda, Dra ${ }^{a}$. Josileide Duarte de Farias, Dra ${ }^{a}$. Maria Izabel Ovellar Heckmann e Dra Marlene Guimarães Santos. A Professora Dra . Maria Manuela da Fonseca Moura chefe do Centro Interdepartamental de Biologia Experimental e Biotecnologia (CIBEBI), onde proporcionou todas as condiçôes burocráticas, físicas e técnicas para que este estudo possa ter sido concretizado. A todos muito obrigado.

\section{BIBLIOGRAFIA CITADA}

Andersson, S.; Mints, M.; Sällström, J.; Wilander, E. 2005. The relative distribution of oncogenic types of human papillomavirus in benign, pre-malignant and malignant cervical biopsies. A study with human papillomavirus deoxyribonucleic acid sequence analysis. Cancer Detection and Prevention, 29: 37-41.

Bernard, P.; Gabant, P.; Bahassi, E.M.; Couturier M. 1994. Positive selection vectors using the F Plasmid $c c d B$ killer gene. Gene, 148: $71-74$.

Bosch, F.X.; Lorincz, A.; Muñoz, N.; Meyjer, C.J.L.M.; Shah, K.V. 2002. The causal relation between human papillomavirus and cervical cancer. Journal of Clinical Pathology, 55: 244-265.
Callahan, R.; Gallahan, D.; Smith, G.; Cropp, C.; Merlo, G.; Diella, F.; Liscia, D. Lidereau, R. 1993. Frequent mutations in breast cancer. Annals of the New York Academy of Sciences, 698: 21-30.

Camara, G.N.N.L.; Cruz M.R.; Veras, V.S.; Martins, C.R.F. 2003. Os papilomavírus humanos-HPV: histórico, morfologia e ciclo biológico. Universitas Ciências da Saúde, 1: 149-158.

Castro, T.M.P.G.; Neto, C.E.R.; Scala, K.A.; Scala, W.A. 2004. Manifestaçóes orais associadas ao papilomavírus humano (HPV) conceitos atuais: revisão bibliográfica. Revista Brasileira de Otorrinolaringologia, 70: 546-550.

Cavalcanti, S.M.B.; Zardo, L.G.; Passos, M.R.L.; Oliveira, L.H.S. 2000. Epidemiological aspects of human papillomavirus infection and cervical cancer in Brazil. Journal of Infection, 40: 80-87.

De Villiers, E.M.; Fauquet, C.; Broker, T.R.; Bernard, H.U.; Zur Hausen, H. 2004. Classification of papillomaviruses. Virology, 324: $17-27$.

Franco, E.L.; Duarte-Franco, E.; Ferenczy, A. 2003. Prospects for controlling cervical cancer at the turn of the century. Salud Pública de México, 45 (supl. 3): 367-375.

Instituto Nacional do Câncer (Brasil). 2008. Câncer do colo do útero. Disponível em: (http://www.inca.gov.br/conteudo). Acesso em: 27/02/2011.

Kaneshima, E.N.; Bidoia, C.C.G.; Gabriel, M.; Suzuki, L.E.; Consolaro, M.E.L. 2001. Aplicação do método PCR-RFLP para tipagem de HPV em infecçóes cervicais de pacientes atendidas no Lepac, Universidade Estadual de Maringá. Acta Scientiarum, 23: 731-737.

Pitta, D.R.; Sarian, L.O.; Capos, E.A.; Rabelo-Santos, S.H.; Syrjänen, K.J.; Derchain, S.F. 2009. Phylogenetic classification of human papillomavirus genotypes in high-grade cervical intraepithelial neoplasia in women from a densely populated Brazilian urban region. São Paulo Medical Journal. 127: 122-127.

Noronha, V.; Mello, W.; Villa, L.L.; Macedo, R.; Bisi, F.; Mota, R, Sassamoto, K.; Monteiro, T.; Linhares, A. 1999. Human papillomavirus associated with cervix lesions. Revista da Sociedade Brasileira de Medicina Tropical, 32: 235-240.

Oliveira, L.H.S.; Rodrigues, E.V.M.; Lopes, A.P.T.A.S. 2003. Human papillomavirus 16 detection in cervical lesions, physical state of viral DNA and changes in p53 gene. São Paulo. Medical Journal, 121:67-71.

Pereyra, E.G.; Parellada, C.I.; Chuery, A.C.S. 2000. Papilomavírus humano. In: Martins NV, Pereyra E.G. (Eds). Conhecendo o HPV: patologia do trato genital inferior, colposcopia e cirurgia de alta freqüiência. Frôntis Editorial $1^{a}$ ed. São Paulo.

Roberts, C.C.; Tadesse, A.S.; Sands, J.; Halvorsen, T.; Schofield, T.L.; Dalen, A.; Skjeldestad, F.E.; Jansen, K.U. 2006. Detection of $\mathrm{HPV}$ in Norwegian cervical biopsy specimens with type-specific PCR and reverse line blot assays. Journal of Clinical Virology, 36: $277-282$. 
Rosa, M.I.; Medeiros, L.R.; Rosa, D.D.; Bozetti, M.C.; Silva, F.R.; Silva, B.R. 2009. Papilomavirus e neoplasia cervical. Cadernos de Saúde Pública, 25: 953-964.

Solomon, D.; Davey, D.; Kurman, R. 2002. The 2001 Bethesda System: terminology for reporting results of cervical cytology. The Journal of the American Medical Association, 287:2114-2119.

Stevens, M.P.; Garland, S.M.; Rudland, E.; Tan, J.; Quinn, M.A.; Tabrizi, S.N. 2007. Comparison of the Digene Hybrid Capture II assay and Roche AMPLICOR and LINEAR ARRAY HPV tests in detecting high-risk HPV genotypes in women with previous abnormal Pap smears. Journal of Clinical Microbiology, 45: 2130-2137.

Wyant, PS. 2007. Caracterização Molecular dos HPVs de Alto Risco dos Genótipos-53, -56 e -66 Infectando Mulheres No Distrito Federal e Entorno. Dissertaçáo de Mestrado. Universidade Federal de Brasília, p. 91.

Recebido em: 04/02/2012

Aceito em: 09/07/2012 